\title{
Biomarkers Detection of Individual PD Symptoms and Therapeutic Effect Prediction with Machine Learning
}

\author{
Quan Zhou ${ }^{1}$, Peng Chen ${ }^{2}$, Chi Xiong' ${ }^{2}$ Chaoshi Niu ${ }^{2,3 *}$ and Ying Wang ${ }^{2,3 *}$ \\ ${ }^{1}$ Hefei Central Sub-branch of the People's Bank of China, Hefei, Anhui Province, PR China \\ ${ }^{2}$ The first affiliated hospital of the University of Science and Technology of China, China \\ ${ }^{3}$ Anhui provincial institute of stereotactic neurosurgery, China
}

*Corresponding author: Chaoshi Niu and Ying Wang, The first affiliated hospital of the University of Science and Technology of China, Anhui provincial institute of stereotactic neurosurgery, China

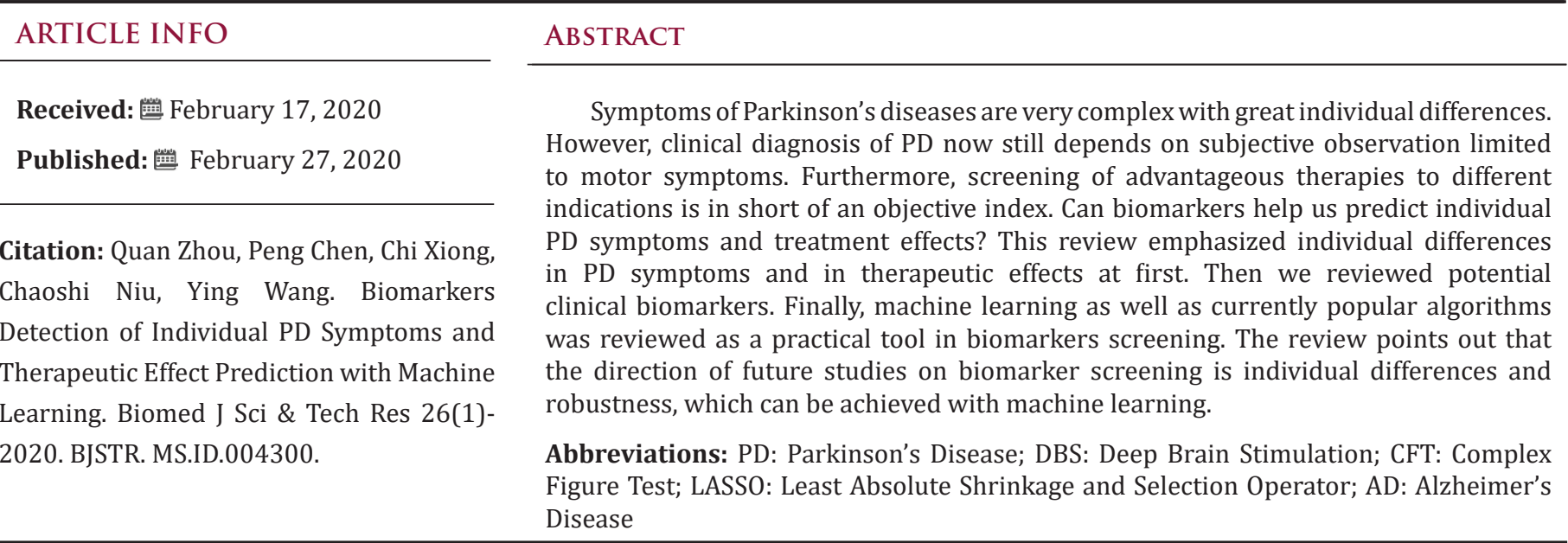

\section{Introduction}

Parkinson's disease (PD) is the second serious neurodegenerative disease only next to the Alzheimer's disease (AD). Almost $1.7 \%$ of the aged more than 65 years old are diagnosed with $\mathrm{PD}$, and the number even reached $4 \%$ in groups older than 80 years [1-4]. Symptoms of PD are very complex with great individual differences. There are typical motor symptoms $[5,6]$ including the static tremor $[7,8]$, muscle rigidity $[9,10]$, bradykinesia and postural balance disorder. There are also non-motor symptoms [11-14] including various cognitive dysfunction [15] (including the verbal disorder, memory loss etc.), anxiety, depression, pain and widely existed sleep disorders, which finally lead to death. However, clinical diagnosis is very subjective and mainly depends on external motor symptoms observation, regardless of individual differences and objectivity. Several common treatments are available including drug therapy, ventrolateral nucleus of thalamus and posteroventral pallidotomy, and the deep brain stimulation (DBS). However, there is no radical treatment of PD. These treatments relieved the PD symptoms with various shortcomings. For example, the effect of drug is limited in the middle and later period of PD, and there are contraindication and side effect of some surgeries [16].

Can biomarkers help us predict the individual PD symptoms and therapeutic effects? This is a big question in clinical diagnosis and individual treatment [17]. A lot of potential biomarkers of neurodegenerative disorders for early diagnose have been studied. For example, the Lewy body detection with PET could be applicable in early diagnose of dementia [18], but the Lewy body is limited in predicting the variabilities. A study on AD found that the PET imaging of tau was related patients' cognitive behavior. It suggests that the PET imaging of tau was the biomarker predicting various cognitive behaviors of AD patients [19]. Of course, this is a result of the "association", and the validation and generalization of the result requires further investigation. As far as we know, this kind of 
study is rare. Most studies only found the effect of certain treatment on some cognitive function, and the effect is just the dichotomy (yes or no). For example, a study with DTI and dosage of l-Dopa could predict the effect of atomoxetine on PD [20]. Although the prediction accuracy reaches $80 \% \sim 85 \%$, the effect is only limited to the inhibition control and is just measured as all or nothing at all. Another study just investigated the tumble of PD patients but no cognitive function or the frequency of tumble [21]. Therefore, the question remains to be investigated.

To address these questions, machine learning is a practical tool [22-28]. Machine learning is an artificial intelligence in nature, and it is an interdisciplinary of probability theory, statistics, approximation theory, convex analysis. The arithmetic of machine learning induces a reliable rule from big data through cross validation and predict a new data. It could be used to make a dichotomy and diversification prediction. Through the cross validation, the core factor in prediction could be found out. For example, the sensitivity and specificity in distinguishing the $\mathrm{AD}$ and healthy control reached $87.1 \%$ and $93.3 \%$ [23]. Another study could even diagnose different stages of $\mathrm{AD}$ with convolutional neural network [29].

\section{Individual PD Symptoms and Therapeutic Effects}

Individual PD Symptoms: Early in 1817, typical motor symptoms of PD were named by a general practitioner James Parkinson in London. He described 6 cases of shaking palsy and denominate these symptoms "Parkinson's Diseases". The motor symptoms are diagnostic criteria in traditional clinic. However, non-motor symptoms, including cognitive impairment [30], neuropsychiatric symptoms (e.g. depression [31], anxiety [32]),

Table 1. autonomic nervous dysfunction (e.g. constipation [33], sleep disorders [34], sensory disturbance [35], pain) are symptoms prior to the motor symptoms. A multiple-sites study in Sydney conducted a 20-year follow-up on 52 PD patients, and the study found these non-motor symptoms were the main causes of disabilities [36]. Non-motor symptoms were not valued in such a long time because the non-motor symptoms in early period were relatively dormant and covered by motor symptoms in later period [37] and because the caregivers or the patients can not precisely report cognitive disabilities [38]. More and more researchers began to pay attention to the non-motor symptoms of PD in recent years.

Among these non-motor symptoms, cognitive disabilities attracted the most attentions for two reasons: first, cognitive functions are the core function, and the damage of non-motor symptoms is the cognitive disability; second, the cognitive disabilities are complex including cognitive control [39], working memory [40-43], language [16,44,45], visual and spatial attention [46]. Executive control means the ability of an individual solving problems and arrangement in limited time and stop-signal no-go task is the commonly used paradigm [47-49]. Working memory was tested with digit span forwards and backwards tasks [47]. Language fluency test was used to test the language fluency [50, 51]. Rey-Osterie complex figure test (CFT) is the usually used test of visual spatial and visual memory $[52,53]$. Alertness and Divided Attention Task and Trail Making test A and B are usually used paradigm for attention [47]. Non-motor symptoms are usually diagnosed with scales. Cognitive function of non-motor symptoms could be measured with paradigms of cognitive neuropsychology (Table 1).

\begin{tabular}{|c|c|c|c|}
\hline \multicolumn{2}{|c|}{ PD symptoms } & Measures \\
\hline Nonmotor & & & Scales (UPDRS, PDQ-39) \\
\hline & Cognitive & & $\begin{array}{c}\text { scales (NMSquest) } \\
\text { scales (MoCA、 Wechsler Memory Scale、Wechsler adult intelligence } \\
\text { scale、Mattis dementia rating scale) }\end{array}$ \\
\hline & & Executive Control & London Tower Test, Stop signal-Nogo task [53] \\
\hline & & Working Memory & digit span forwards and backwards task \\
\hline & & Language & Rey-Osterrieth complex figure test \\
\hline & & Visual Spatial and Visual Memory & Alertness and Divided Attention Task and Trail Making test A and B \\
\hline & & Attention & scales (MMSE, HAMD, PDQI, Constipation scale, PDSS-CV) \\
\hline
\end{tabular}

Note: UPDRS: United Pd Rating Scales; PDQ-39: Parkinson's Disease Questionnaire; NMSquest: Non-Motor Questionnaire; MoCA: Monte Carlo Cognitive Assessment; MMSE: Mini-Mental State Examination; HAMD: Hamilton Depression Scale; PDQI: Pittsburgh Sleep Quality Scale; PDSS-CV: PD Sleep Scales.

History of Available Therapies and Related Effects: Currently, PD is mainly treated with drugs and surgery. The drug is mainly levodopa, and the surgery is mainly the posterior section of the ventral nucleus or Globus pallidum of the thalamus and the deep brain stimulation developed in recent years. Surgery and drugs have led alternately in the history of PD treatment and are now in a state of union. In 1817, James Parkinson noticed in a patient that the tremor disappeared dramatically after a cerebral hemorrhage in the contralateral side. This record may be the first conscious recognition of the science of the treatment of PD brain 
disorientation. From the brain to the spinal cord, from the surface of the brain to the deep brain structure, in order to eliminate the symptoms of motor dysfunction, surgery involves almost all motion-related structures in recent 100 years. The early curative effect of surgery is often that the disappearance of tremor is often accompanied by the occurrence of hemiplegia and the recovery of hemiplegia accompanied by the recurrence of tremor. In 1941, Russel Meyers established the extrapyramidal surgery. He first excised the head of the caudate nucleus, and later switched to other structures in the basal ganglia, such as the forelimbs of the inner capsule. Meyers's pioneering work has demonstrated that tremor can be treated without paralysis.

But rough technique led to a mortality rate of more than 15 percent. In 1947, in the United States, Spiegel and Wyss et al. applied the stereotactic neurophysiology to clinical treatment of motor disorders and psychosis, which established the independent clinical branch of stereotactic neurosurgery. Since the new method was first reported by academician Zhong cheng Wang in China in the 1960s, stereotactic surgery has been carried out in Beijing, Shanghai, Anhui and Shaanxi, and many Parkinson's patients have been treated. In 1961, Holnikiewicz and Walter bicker Meier, of the university of Vienna, gave patients the drug levodopa, a precursor to dopamine, after discovering that lower levels of dopamine are the pathology of PD. Within hours of taking the drug, patients who are unable to move can move again, and the effect lasts a day. Levodopa was approved in 1970. Since then, other dopamine-based treatments have emerged. In addition, since the target location is not accurate enough and the size of the lesion is difficult to control, there are many postoperative complications, which limits the indepth development of stereotactic surgery.

At that time, few people are going to receive surgical treatment, which significantly reduces the source of disease requiring surgery, and the stereotactic surgery to treat Parkinson's disease is also in an ebb. In the late 1970s, the shortcomings of levodopa gradually came to light, and its curative effect decreased with the development of the disease. Meanwhile, a series of side effects, such as "on-off" phenomenon, dysplasia, and end-agent phenomenon, made the surgical treatment of Parkinson's disease regain people's attention. Deep brain stimulation surgery was developed in the late 1970s and was first used to treat pain. In 1987, French Benabid applied DBS to stimulate the hypothalamus to treat the tremor of Parkinson's disease and achieved success, opening a new era for the treatment of PD by DBS. The advantage of DBS is non-destructive, reversible, with few side effects and complications, and DBS can be adjusted to achieve the best control of symptoms with long-term effective. No matter the DBS or other operations, the accuracy of target localization is the key to the success of the operation.

With the development of neuroimaging technology, neuro electrophysiological detection technology and microelectrode technology, under the guidance of MRI, the relationship between the position, size and the surrounding important structures of brain kernels as targets can be clearly observed. However, individual differences in the treatment process are significant, with each treatment regimen having its indication type (Table 2). Deep brain stimulation, which is clearly indicated in the NIH treatment guidelines, is not appropriate for patients with severe cognitive impairment because there are still some side effects with DBS. For example, several articles reported that patients with Parkinson's disease had faster decision-making speed when facing difficult problems after DBS, namely impulsive behavior [54]. Phillips et al. fount that $32 \%$ patients appeared dementia within 2 year-follow up after DBS, but only $16 \%$ patients appeared dementia in control group [55]. DBS can also cause a decline in executive or language functions [56,57]. The choice of electrode guided stereotactic disfigurement should satisfy at least three principles: the diagnosis of primary Parkinson's disease; levodopa is effective in treatment; good cognitive function and good cooperation. The selection of damage targets is mainly determined according to clinical symptoms.

Table 2.

\begin{tabular}{|c|c|c|c|c|c|}
\hline Type of surgery & Tremble & Rigidity & Dilatory & Dyskinesia & Gait \\
\hline pallidotomy & $+/++$ & $+/++$ & ++ & + \\
\hline thalamotomy & ++ & $+/++$ & - & $+/++$ & + \\
\hline DBS & ++ & + & - & + \\
\hline
\end{tabular}

The posterior and medial parts of the Globus pallidus were used as the routine therapeutic target. If the tremor symptoms did not improve significantly during the operation, the ventral nucleus of the thalamus was added. The ventral nucleus of the thalamus can be selected as the target for pure tremor type patients. There are many factors influencing the treatment effect, including the age of onset, the incidence side of movement disorder, drug dosage, and the location of electrode implantation [13]. Even different types of anesthesia may have different effects on postoperative cognitive function $[58,59]$.
Potential Biomarkers: In 1912, German neurologists Frederick Louis and Alessandro Alzheimer stained the brains of dead Parkinson's patients. Among neurons under multiple subcortical nuclei, Louis found abnormal protein aggregation, and later generations gave his name to this protein aggregate the Lewy body [60-63]. Since then, discussion about the Lewy bodies and the Parkinson's disease continues to this day. Neurologist Konstantin Tretyakov found that the loss of neurons in the substantia nigra of the brain is a pathological marker of Parkinson's disease. Other researchers, however, believed that the pathology of Parkinson's disease originated in a part of the brain called the striatum [2,5,64-66]. 
In 1960, Oleg Hornikiewicz and Herbert Ellinger of the university of Vienna studied the levels of dopamine in the brains of two Parkinson's patients and four post-encephalitis Parkinson's patients. In all these samples, levels of dopamine in the brain were lower than in the normal brain. A few years later, researchers found that dopamine in the striatum came from neurons that the substantia nigra projected onto the striatum with the help of high-resolution PET $[4,67,68]$. Therefore, biochemical including the dopamine could be considered as potential biomarkers.

In June 1997, at the national institutes of health in Bethesda, Maryland, a team led by geneticist Michael polyamorous discovered a gene mutation that could cause a type of inherited Parkinson's disease. This gene is responsible for the synthesis of synuclein. Since then, its diploid and triploid genes have been found to cause Parkinson's disease, and other genetic mutations have been linked to rare genetic cases. By now, dozens of pd-related genes have been identified [69-71], including the LRRK2 [72-74], SNCA [75-77], GBA [78-81], PARK [82,83], COMT [84-86], APOE [87,88], MAPT [89-91]. LRRK2 is one of most studied PD-related genes. Interestingly, its most common mutation, G2019S (common in Ashkenazi and north African populations and extremely rare in Asian populations) will not worsen the overall cognitive decline of patients, but reduce the risk of dementia; PD patients with SNCA gene mutation have cortical spongiform changes in addition to Louie in vitro, early onset, rapid progression and high incidence of dementia. A follow-up study with a sample size of 4 million over 11 years showed that the severity of mutations in the GBA gene varied, as did the symptoms of PD [79].

The relationship between this genetic diversity and the diversity of cognitive dysfunction predicts important potential biological markers. And therefore, blood samples and saliva samples for PD-related gene or protein analyses should be considered as potential biomarkers. With the development of neuroimaging, such as PET and MRI, some scholars have pointed out that MRI structure images are more likely to become reliable biological markers [17]. Cerebrospinal fluid (e.g., A aspir42), gray matter, white matter $[50,92]$ and metabolic levels of many metabolites (e.g., 18f-fdg) all indicate the occurrence and development of PD. Studies have shown that the gray matter volume of the hippocampal and thalamus of preoperative MRI is correlated with the changes of language memory performance before and after surgery [16]. A five-year tracking MRI study with sample size of 168 Parkinson's cases, divided the patients into serious atrophy and not serious atrophy according to the size of cholinergic basal forebrain, and found the degree of atrophy was significantly associated with the decrease of memory and language fluency of the patients 5 years after the surgery [3]. It prompts that the multiple-modal biological indicators should consider cholinergic biological basis.

Another similar MRI study found that the decline of gray matter volume and the increase of white matter diffusion in basal nuclei was correlated with the cognitive disabilities, and this result was not found in other brain areas such as the entorhinal cortex, amygdala, insula, hippocampus and thalamus [93]. A study based on PD without cognitive impairment found that these patients had no significant atrophy of gray matter compared to normal people, but extensive changes in white matter had occurred, suggesting that white matter may be a biological indicator prior to both gray matter and cognitive changes [50]. A method of whole-brain voxel analysis using multimodality MRI data (white and gray matter) and supervising/non-supervising classification algorithm can accurately distinguish PD from other diseases [94]. An MRI study suggests that the structural density of different subregions of the substantia nigra is related to the development of PD. Other studies have suggested a correlation between the level of brain functional connectivity in PD symptoms and progression [1, 95, 96]. These results suggest that the structural features of conventional MRI, including white and gray matter, and brain functional connectivity, may be useful predictors of biology [30].

Machine Learning - A Practical Tool: Machine learning is another name of pattern recognition, including unsupervised learning, supervised learning and reinforcement learning. Classification is one of the most important goal of machine learning (especially supervised learning). Here we briefly reviewed supervised learning as well as algorithms, including linear and non-linear classifiers. Logistic regression and K-Nearest Neighbors Algorithm are frequently used linear classifiers. In a recent study, multivariate regression analyses were applied to the resting-state functional MRI data, and it reported that pretreatment functional connectivity patterns within the default mode network and visual network significantly predicted posttreatment obsessivecompulsive disorder severity, explaining up to $67 \%$ of the variance [97]. Non-linear classifier mainly includes support vector machines (SVM) and neural network (especially recently developed deep learning).SVM is usually used for dichotomy and requires controlled features. But deep learning supports multi-classification and screens features automatically. Convolutional neural network is the most popular deep learning algorithm [29,98-100]. Several tools are available for algorithm optimization, including the TensorFlow, torch, Theano, caffe etc..

Recently, there have been many different new algorithms that support our classification. A study with 92 features including MRI, PET and cerebrospinal fluid used multiple modal extremely sparse layer algorithm (multimodal sparse hierarchical extreme SVM) and dissociated AD from normal controls with 96.1\% accuracy [22]. A study using the convolution neural network algorithm could diagnose and predict the different stages of AD [29]. Another study used convolutional neural networks to diagnose subcortical underdevelopment, and the code for the related algorithms is open source [98]. The overall process and algorithm architecture of this study are shown in (Figure 1). 
a.

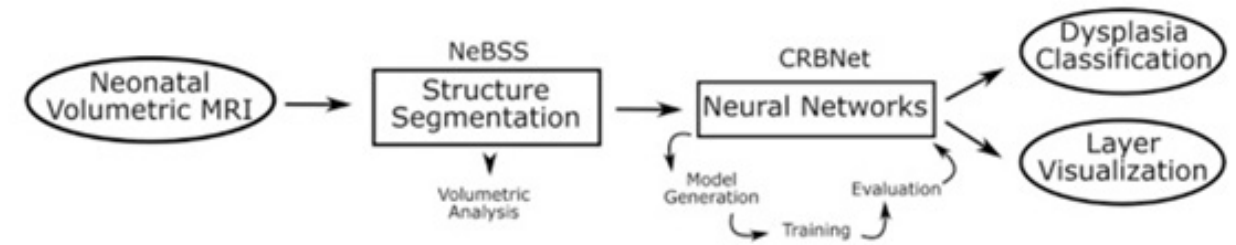

b.

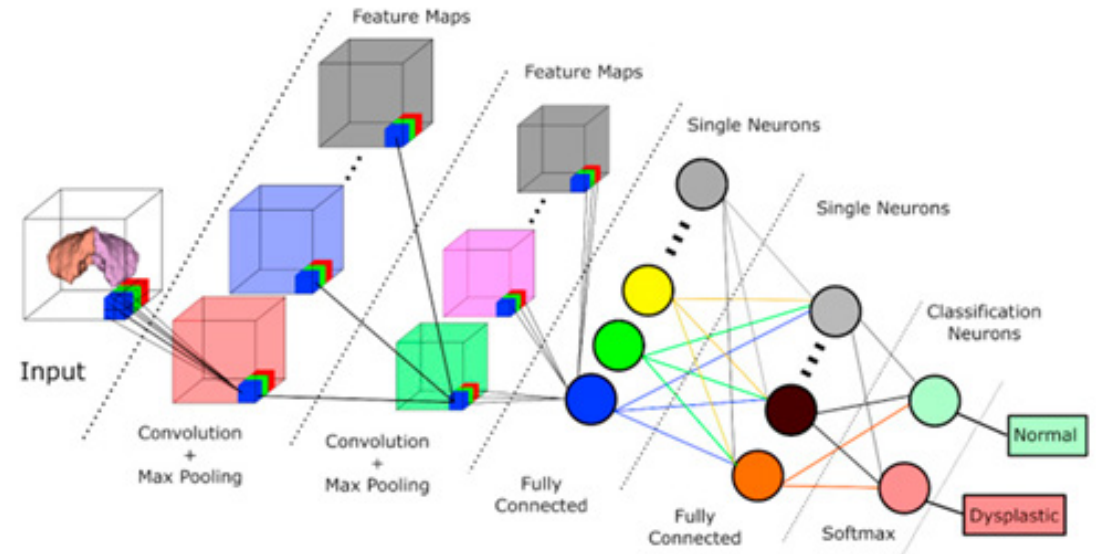

Figure 1: The study of convolution neural network was used to diagnose subcortical immature structures.

a) the overall process of the study.

b) algorithm architecture. The evolution of PD therapeutic methods and effect evaluation.

Feature selection is a core question in supervised learning. To minimize the generalization error, in other word, to minimize the underfitting and overfitting, is the guide of feature selection. The correlation between the features and the predicted results is usually used but not enough and limited because the relationship may be mediated by other factors or may be non-linear. Ergodic combination of features or greedy feature selection are usually used. However, the best choice is regularization with a least absolute shrinkage and selection operator [LASSO] regression model [97] or Ridge Regression model.

\section{Conclusion}

This review provides an overview of PD-related studies and proposes individual symptoms of PD should be appreciated in biomarker screening, especially increasingly attention-getting non-motor symptoms. Some potential biomarkers as well as the advantage of the machine learning in biomarker screening is reviewed. The review points out that the direction of future studies on biomarker screening is individual differences and robustness, which can be achieved with machine learning.

\section{References}

1. Yau, Y, Zeighami Y, Baker TE, Larcher K, Vainik U, et al. (2018) Network connectivity determines cortical thinning in early Parkinson's disease progression. Nature Communications 9.
2. Suarez LM (2018) Differential Synaptic Remodeling by Dopamine in Direct and Indirect Striatal Projection Neurons in Pitx3(-/-) Mice, a Genetic Model of Parkinson's Disease. J Neurosci 38(15): 3619-3630.

3. Ray NJ, Bradburn S, Murgatroyd C, Toseeb U, Mir P, et al. (2018) In vivo cholinergic basal forebrain atrophy predicts cognitive decline in de novo Parkinson's disease. Brain 141(1): 165-176.

4. Nettersheim FS, Loehrer PA, Weber I, Jung F, Dembek TA, et al. (2019) Dopamine substitution alters effective connectivity of cortical prefrontal, premotor, and motor regions during complex bimanual finger movements in Parkinson's disease. Neuroimage 190: 118-132.

5. Kawashima S, Ueki Y, Kato T, Ito K, Matsukawa N, et al. (2018) Reduced striatal dopamine release during motor skill acquisition in Parkinson's disease. PLoS One 13(5): e0196661.

6. Gallese V, V Cuccio (2018) The neural exploitation hypothesis and its implications for an embodied approach to language and cognition: Insights from the study of action verbs processing and motor disorders in Parkinson's disease. Cortex 100: 215-225.

7. Pasquini J, Ceravolo R, Qamhawi Z, Lee JY, Deuschl G, et al. (2018) Progression of tremor in early stages of Parkinson's disease: A clinical and neuroimaging study. Brain 141(3): 811-821.

8. Agapaki OM, CN Christakos, D Anastasopoulos (2018) Characteristics of Rest and Postural Tremors in Parkinson's Disease: An Analysis of Motor Unit Firing Synchrony and Patterns. Frontiers in Human Neuroscience 12: 79 .

9. Cano de la Cuerda R (2017) Axial rigidity is related to the risk of falls in patients with Parkinson's disease. Neuro Rehabilitation 40(4): 569-577.

10. Hou Y, Luo C, Yang J, Ou R, Liu W, et al. (2017) Default-mode network connectivity in cognitively unimpaired drug-naive patients with rigiditydominant Parkinson's disease. J Neurol 264(1): 152-160. 
11. Arie L (2017) Do cognition and other non-motor symptoms decline similarly among patients with Parkinson's disease motor subtypes? Findings from a 5-year prospective study. J Neurol 264(10): 2149-2157.

12. Bonnet AM, V Czernecki (2013) Non-motor symptoms in Parkinson's disease: Cognition and behavior. Geriatr Psychol Neuropsychiatr Vieil 11(3): 295-304.

13. Dafsari HS, Petry Schmeltzer JN, Ray Chaudhuri K, Ashkan K, Weis L, Dembek TA, et al. (2018) Non-motor outcomes of subthalamic stimulation in Parkinson's disease depend on location of active contacts. Brain Stimul 11(4): 904-912.

14. Menza M, Roseanne DeFranzo Dobkin, Humberto Marin, Margery H Mark, Michael Gara, et al. (2010) The role of inflammatory cytokines in cognition and other non-motor symptoms of Parkinson's disease. Psychosomatics 51(6): 474-479.

15. Abur D, Rosemary A Lester Smith, Frank H Guenther, Ashling A Lupiani, Cara E Stepp, et al. (2018) Sensorimotor adaptation of voice fundamental frequency in Parkinson's disease. PLoS One 13(1): e0191839.

16. Gee Varghese R, Daniel E Lumsden, Angela Costello, Natasha Hulse, Salma Ayis, et al. (2016) Verbal Memory Decline following DBS for Parkinson's Disease: Structural Volumetric MRI Relationships. PLoS One 11(8): e0160583.

17. Husain M (2017) How far can biomarkers take us in neurodegenerative disorders? Brain 140: 3067-3068.

18. McKeith IG, Boeve BF, Dickson DW, Halliday G, Taylor JP, et al. (2017) Diagnosis and management of dementia with Lewy bodies: Fourth consensus report of the DLB Consortium. Neurology 89(1): 88-100.

19. Bejanin A, Schonhaut DR, La Joie R, Kramer JH, Baker SL, et al. (2017) Tau pathology and neurodegeneration contribute to cognitive impairment in Alzheimer's disease. Brain 140(12): 3286-3300.

20. Ye Z, Rae CL, Nombela C, Ham T, Rittman T, et al. (2016) Predicting beneficial effects of atomoxetine and citalopram on response inhibition in Parkinson's disease with clinical and neuroimaging measures. Hum Brain Mapp 37(3): 1026-1037.

21. Gao C, Hanbo Sun, Tuo Wang, Ming Tang, Nicolaas I Bohnen, et al (2018) Model-based and Model-free Machine Learning Techniques for Diagnostic Prediction and Classification of Clinical Outcomes in Parkinson's Disease. Sci Rep 8(1): 7129.

22. Kim J, B Lee (2018) Identification of Alzheimer's disease and mild cognitive impairment using multimodal sparse hierarchical extreme learning machine. Hum Brain Mapp 39(9): 3728-3741.

23. Lee JS, Kim C, Shin JH, Cho H, Shin DS, et al. (2018) Machine Learningbased Individual Assessment of Cortical Atrophy Pattern in Alzheimer's Disease Spectrum: Development of the Classifier and Longitudinal Evaluation. Sci Rep 8(1): 4161.

24. Savage N (2017) Machine learning: Calculating disease. Nature 550(7676): S115-S117.

25. Zhang B, Wan X, Ouyang FS, Dong YH, Luo DH, et al. (2017) Machine Learning Algorithms for Risk Prediction of Severe Hand-Foot-Mouth Disease in Children. Sci Rep 7(1): 5368.

26. Zhao Y, Healy BC, Rotstein D, Guttmann CR, Bakshi R, et al. (2017) Exploration of machine learning techniques in predicting multiple sclerosis disease course. PLoS One 12(4): e0174866.

27. Crimi A, Commowick O, Maarouf A, Ferré JC, Bannier E, et al. (2014) Predictive value of imaging markers at multiple sclerosis disease onset based on gadolinium- and USPIO-enhanced MRI and machine learning. PLoS One 9(4): e93024.

28. Rizk Jackson A, Stoffers D, Sheldon S, Kuperman J, Dale A, et al. (2011) Evaluating imaging biomarkers for neurodegeneration in presymptomatic Huntington's disease using machine learning techniques. Neuroimage 56(2): 788-796.
29. Islam J, Y Zhang (2018) Brain MRI analysis for Alzheimer's disease diagnosis using an ensemble system of deep convolutional neural networks. Brain Inform 5(2): 2.

30. Lawson RA, Collerton D, Taylor JP, Burn DJ, Brittain KR, et al. (2018) Coping with Cognitive Impairment in People with Parkinson's Disease and Their Careers: A Qualitative Study. Parkinson Dis 2018: 1362053.

31. Fang F, Qun Xu, Yikyung Park, Xuemei Huang, Albert Hollenbeck, et al. (2010) Depression and the subsequent risk of Parkinson's disease in the NIH-AARP Diet and Health Study. Mov Disord 25(9): 1157-1162.

32. Weisskopf MG, Chen H, Schwarzschild MA, Kawachi I, Ascherio A, et al. (2003) Prospective study of phobic anxiety and risk of Parkinson's disease. Mov Disord 18(6): 646-651.

33. Adams Carr KL, Bestwick JP, Shribman S, Lees A, Schrag A, et al. (2016) Constipation preceding Parkinson's disease: A systematic review and meta-analysis. J Neurol Neurosurg Psychiatry 87(7): 710-716.

34. Claassen DO, KA Josephs, JE Ahlskog, MH Silber, M Tippmann Peikert, et al. (2010) REM sleep behavior disorder preceding other aspects of synucleinopathies by up to half a century. Neurology 75(6): 494-499.

35. Ross GW, Petrovitch H, Abbott RD, Tanner CM, Popper J, et al. (2008) Association of olfactory dysfunction with risk for future Parkinson's disease. Ann Neurol 63(2): 167-173.

36. Vingerhoets FJ, Villemure JG, Temperli P, Pollo C, Pralong E, et al. (2002) Subthalamic DBS replaces levodopa in Parkinson's disease: Two-year follow-up. Neurology 58(3): 396-401.

37. Benabid AL, Koudsié A, Pollak P, Kahane P, Chabardes S, et al. (2000) Future prospects of brain stimulation. Neurol Res 22(3): 237-246.

38. Copeland JN (2016) Accuracy of Patient and Care Partner Identification of Cognitive Impairments in Parkinson's Disease-Mild Cognitive Impairment. Mov Disord 31(5): 693-698.

39. Walton CC, Shine JM, Mowszowski L, Gilat M, Hall JM, et al. (2015) Impaired cognitive control in Parkinson's disease patients with freezing of gait in response to cognitive load. J Neural Transm (Vienna) 122(5): 653-660.

40. Degos B, Ilhame Ameqrane, Sophie Rivaud Péchoux, Pierre Pouget, Marcus Missal, et al. (2018) Short-term temporal memory in idiopathic and Parkin-associated Parkinson's disease. Sci Rep 8(1): 7637.

41. Fallon SJ, Mattiesing RM, Muhammed K, Manohar S, Husain M, et al. (2017) Fractionating the Neurocognitive Mechanisms Underlying Working Memory: Independent Effects of Dopamine and Parkinson's Disease. Cereb Cortex 27(12): 5727-5738.

42. Fallon SJ, Bor D, Hampshire A, Barker RA, Owen AM, et al. (2017) Spatial structure normalizes working memory performance in Parkinson's disease. Cortex 96: 73-82.

43. Simioni AC, A Dagher LK (2017) Fellows Effects of levodopa on corticostriatal circuits supporting working memory in Parkinson's disease. Cortex 93: 193-205.

44. Gauvin HS, Mertens J, Mariën P, Santens P, Pickut BA, et al. (2017) Verbal monitoring in Parkinson's disease: A comparison between internal and external monitoring. PLoS One 12(8): e0182159.

45. Demeter G, Valálik I, Pajkossy P, Szőllősi Á, Lukács Á, et al. (2017) The effect of deep brain stimulation of the subthalamic nucleus on executive functions: impaired verbal fluency and intact updating, planning and conflict resolution in Parkinson's disease. Neurosci Lett 647: 72-77.

46. Norton DJ, Victoria A Nguyen, Michaela F Lewis, Gretchen O Reynolds, David C Somers, et al. (2016) Visuospatial Attention to Single and Multiple Objects Is Independently Impaired in Parkinson's Disease. PLoS One 11(3): e0150013.

47. Ruprecht Dorfler P, Berg D, Tucha O, Benz P, Alders GL, et al. (2003) Echogenicity of the substantia nigra in relatives of patients with sporadic Parkinson's disease. Neuroimage 18(2): 416-422. 
48. Cools R, Elka Stefanova, Roger A Barker, Trevor W Robbins, Adrian M Owen, et al. (2002) Dopaminergic modulation of high-level cognition in Parkinson's disease: The role of the prefrontal cortex revealed by PET. Brain 125(Pt 3): 584-594.

49. Owen AM, James M, Leigh PN, Summers BA, Marsden CD, et al. (1992) Fronto-striatal cognitive deficits at different stages of Parkinson's disease. Brain 115 ( Pt 6): 1727-1751.

50. Rektor I, Svátková A, Vojtíšek L, Zikmundová I, Vaníček J, et al. (2018) White matter alterations in Parkinson's disease with normal cognition precede grey matter atrophy. PLoS One 13(1): e0187939.

51. Darweesh SK, Verlinden VJ, Stricker BH, Hofman A, Koudstaal PJ, et al. (2017) Trajectories of prediagnostic functioning in Parkinson's disease. Brain 140(2): 429-441.

52. Kim K (2018) Compensatory dopaminergic-cholinergic interactions in conflict processing: Evidence from patients with Parkinson's disease. Neuroimage.

53. Ye Z, Altena E, Nombela C, Housden CR, Maxwell H, et al. (2014) Selective serotonin reuptake inhibition modulates response inhibition in Parkinson's disease. Brain 137(Pt 4): 1145-1155.

54. Frank MJ (2007) Hold your horses: Impulsivity, deep brain stimulation, and medication in parkinsonism. Science 318(5854): 1309-1312.

55. Phillips L, Litcofsky KA, Pelster M, Gelfand M, Ullman MT, et al. (2012) Subthalamic nucleus deep brain stimulation impacts language in early Parkinson's disease. PLoS One 7(8): e42829.

56. Halpern CH, Rick JH, Danish SF, Grossman M, Baltuch GH, et al. (2009) Cognition following bilateral deep brain stimulation surgery of the subthalamic nucleus for Parkinson's disease. Int J Geriatr Psychiatry 24(5): 443-451.

57. Follett KA, Weaver FM, Stern M, Hur K, Harris CL, et al. (2010) Pallida versus Subthalamic Deep-Brain Stimulation for Parkinson's Disease. New England Journal of Medicine 362(22): 2077-2091.

58. Yamada K, Goto S, Kuratsu J, Matsuzaki K, Tamura T, et al. (2007) Stereotactic surgery for subthalamic nucleus stimulation under general anesthesia: A retrospective evaluation of Japanese patients with Parkinson's disease. Parkinsonism Relat Disord 13(2): 101-107.

59. Furuya R, Hirai A, Andoh T, Kudoh I, Okumura F, et al. (1998) Successful perioperative management of a patient with Parkinson's disease by enteral levodopa administration under propofol anesthesia. Anesthesiology 89(1): 261-263.

60. Wood PL (2018) Augmented frontal cortex diacylglycerol levels in Parkinson's disease and Lewy Body Disease. PLoS One 13(3): e0191815.

61. Ejlerskov P, Jeanette Göransdotter Hultberg, Jun Yang Wang, Robert Carlsson, Malene Ambjørn, et al. (2015) Lack of Neuronal IFN-betaIFNAR Causes Lewy Body- and Parkinson's Disease-like Dementia. Cell 163(2): 324-339.

62. Scullin MK, Lynn Marie Trotti, Anthony G Wilson, Sophia A Greer, Donald L Bliwise, et al. (2012) Nocturnal sleep enhances working memory training in Parkinson's disease but not Lewy body dementia. Brain 135(9): 2789-2797.

63. Forno LS (1987) The Lewy body in Parkinson's disease. Adv Neurol 45 35-43.

64. Giordano N, Iemolo A, Mancini M, Cacace F, De Risi M, et al. (2018) Motor learning and met plasticity in striatal neurons: Relevance for Parkinson's disease. Brain 141(2): 505-520.

65. Petersen K, Van Wouwe N, Stark A, Lin YC, Kang H, et al. (2018) Ventral striatal network connectivity reflects reward learning and behavior in patients with Parkinson's disease. Hum Brain Mapp 39(1): 509-521.

66. Tanimura A, Pancani T, Lim SAO, Tubert C, Melendez AE, et al. (2018) Striatal cholinergic interneurons and Parkinson's disease. Eur J Neurosci 47(10): 1148-1158.
67. Le Heron C, Plant O, Manohar S, Ang YS, Jackson M, et al. (2018) Distinct effects of apathy and dopamine on effort-based decision-making in Parkinson's disease. Brain 141(5): 1455-1469.

68. Fazio P, Svenningsson P, Cselényi Z, Halldin C, Farde L, et al. (2018) Nigrostriatal dopamine transporter availability in early Parkinson's disease. Mov Disord 33(4): 592-599.

69. Robak LA, Jansen IE, Van Rooij J, Uitterlinden AG, Kraaij R, et al. (2017) Excessive burden of lysosomal storage disorder gene variants in Parkinson's disease. Brain 140(12): 3191-3203.

70. Mittal S, Bjørnevik K, Im DS, Flierl A, Dong X, et al. (2017) Beta2Adrenoreceptor is a regulator of the alpha-synuclein gene driving risk of Parkinson's disease. Science 357(6354): 891-898.

71. Shi CH, Fang Li, Meng-meng Shi, Zhi-hua Yang, Cheng-yuan Mao, et al. (2017) Genetic analysis of the TMEM230 gene in Chinese Han patients with Parkinson's disease. Sci Rep 7(1): 1190.

72. Roosen DA, AB Singleton (2018) Leucine rich repeat kinase knockout (LRRK KO) mouse model: Linking pathological hallmarks of inherited and sporadic Parkinson's disease. Mov Disord 33(1): 72.

73. Quintero Espinosa D, M Jimenez Del Rio, C Velez Pardo (2017) Knockdown transgenic Lrrk Drosophila resists paraquat-induced locomotor impairment and neurodegeneration: A therapeutic strategy for Parkinson's disease. Brain Res 1657: 253-261.

74. Bialecka M, Hui S, Klodowska Duda G, Opala G, Tan EK, et al. (2005) Analysis of LRRK 2 G 2019 S and I 2020 T mutations in Parkinson's disease. Neurosci Lett 390(1): 1-3.

75. Mokretar K, Pease D, Taanman JW, Soenmez A, Ejaz A, et al. (2018) Somatic copy number gains of alpha-synuclein (SNCA) in Parkinson's disease and multiple system atrophy brains. Brain 141(8): 2419-2431.

76. Konno T, J Siuda, ZK Wszolek (2016) Genetics of Parkinson's disease: A review of SNCA and LRRK2. Wiad Lek 69(3 Pt 1): 328-332.

77. Li NN, Mao XY, Chang XL, Zhao DM, Zhang JH, et al. (2013) SNCA rs356219 variant increases risk of sporadic Parkinson's disease in ethnic Chinese. Am J Med Genet B Neuropsychiatr Genet 162B(5): 452-456.

78. Alcalay RN, Levy OA, Waters CC, Fahn S, Ford B, et al. (2015) Glucocerebrosidase activity in Parkinson's disease with and without GBA mutations. Brain 138(Pt 9): 2648-2658.

79. Gan or Z, N Giladi, A Orr Urtreger (2009) Differential phenotype in Parkinson's disease patients with severe versus mild GBA mutations. Brain 132(Pt 10): e125.

80. Taguchi YV, Liu J, Ruan J, Pacheco J, Zhang X, et al. (2017) Glucosyl sphingosine Promotes alpha-Synuclein Pathology in Mutant GBAAssociated Parkinson's Disease. J Neurosci 37(40): 9617-9631.

81.Zokaei N, McNeill A, Proukakis C, Beavan M, Jarman P, et al. (2014) Visual short-term memory deficits associated with GBA mutation and Parkinson's disease. Brain 137(Pt 8): 2303-2311.

82. Fiala O, Daniela Zahorakova, Lenka Pospisilova, Jana Kucerova, Milada Matejckova, et al. (2014) Parkin (PARK 2) mutations are rare in Czech patients with early-onset Parkinson's disease. PLoS One 9(9): e107585.

83. Chung SJ, Sebastian M Armasu, Joanna M Biernacka, Timothy G Lesnick, David N Rider, et al. (2011) Common variants in PARK loci and related genes and Parkinson's disease. Mov Disord 26(2): 280-288.

84. Lin CH, Chaudhuri KR, Fan JY, Ko CI, Rizos A, et al. (2017) Depression and Catechol-0-methyltransferase (COMT) genetic variants are associated with pain in Parkinson's disease. Sci Rep 7(1): 6306.

85. Williams Gray CH (2008) Attentional control in Parkinson's disease is dependent on COMT val 158 met genotype. Brain 131(Pt 2): 397-408.

86. Tropea TF, Xie SX, Rick J, Chahine LM, Dahodwala N, et al. (2018) APOE, thought disorder, and SPARE-AD predict cognitive decline in established Parkinson's disease. Mov Disord 33(2): 289-297. 
87. Cervantes Arriaga A, Rodríguez-Violante M, González-Latapí P, DávilaOrtiz de Montellano DJ, Yescas P, et al. (2014) ApoE polymorphisms and dopaminergic replacement therapy in Parkinson's disease. Rev Med Inst Mex Seguro Soc 52(1): 14-18.

88. Papa Petropoulos S, Farrer MJ, Stone JT, Milkovic NM, Ross OA, et al. (2007) Phenotypic associations of tau and ApoE in Parkinson's disease. Neurosci Lett 414(2): 141-144.

89. Li J, Ruskey JA, Arnulf I, Dauvilliers Y, Hu MTM, et al. (2018) Ful sequencing and haplotype analysis of MAPT in Parkinson's disease and rapid eye movement sleep behavior disorder. Mov Disord 33(6): 10161020.

90. Coupland KG, Kim WS, Halliday GM, Hallupp M, Dobson-Stone C, et al. (2016) Role of the Long Non-Coding RNA MAPT-AS1 in Regulation of Microtubule Associated Protein Tau (MAPT) Expression in Parkinson's Disease. PLoS One 11(6): e0157924.

91. Coupland KG, Mellick GD, Silburn PA, Mather K, Armstrong NJ, et al. (2014) DNA methylation of the MAPT gene in Parkinson's disease cohorts and modulation by vitamin E in vitro. Mov Disord 29(13): 16061614

92. Mak E (2015) Neuroimaging correlates of cognitive impairment and dementia in Parkinson's disease. Parkinsonism Relat Disord 21(8): 862870.

93. Schulz J, Gennaro Pagano, Juan Alberto Fernández Bonfante, Heather Wilson, Marios Politis, et al. (2018) Nucleus basalis of Meynert degeneration precedes and predicts cognitive impairment in Parkinson's disease. Brain 141: 1501-1516.

\section{ISSN: 2574-1241}

DOI: $10.26717 /$ BJSTR.2020.26.004300

Ying Wang. Biomed J Sci \& Tech Res

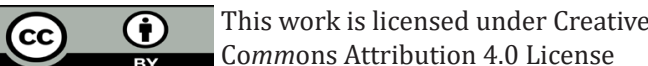

Submission Link: https://biomedres.us/submit-manuscript.php
94. Peran, P, Barbagallo G, Nemmi F, Sierra M, Galitzky M, et al. (2018) MRI supervised and unsupervised classification of Parkinson's disease and multiple system atrophy. Movement Disorders 33(4): 600-608.

95. Amoroso N, La Rocca M, Monaco A, Bellotti R, Tangaro S, et al. (2018) Complex networks reveal early MRI markers of Parkinson's disease. Med Image Anal 48: 12-24.

96. Plantinga BR, Temel Y, Duchin Y, Uludağ K, Patriat R, et al. (2018) Individualized parcellation of the subthalamic nucleus in patients with Parkinson's disease with 7T MRI. Neuroimage 168: 403-411.

97. Reggente N, Moody TD, Morfini F, Sheen C, Rissman J, et al. (2018) Multivariate resting-state functional connectivity predicts response to cognitive behavioral therapy in obsessive-compulsive disorder. Proc Natl Acad Sci U S A 115(9): 2222-2227.

98. Ceschin R, Zahner A, Reynolds W, Gaesser J, Zuccoli G, et al. (2018) A computational framework for the detection of subcortical brain dysmaturation in neonatal MRI using 3D Convolutional Neural Networks. Neuroimage 178: 183-197.

99. Kang SK, Seo S, Shin SA, Byun MS, Lee DY, et al. (2018) Adaptive template generation for amyloid PET using a deep learning approach. Hum Brain Mapp 39(9): 3769-3778.

100. Ktena SI, Sarah Parisot, Enzo Ferrante, Martin Rajchl, Matthew Lee, et al. (2018) Metric learning with spectral graph convolutions on brain connectivity networks. Neuroimage 169: 431-442.

$\begin{array}{ll}\text { BIOMEDICAL } & \text { Assets of Publishing with us } \\ \text { RESEARCHES } & \text { - Global archiving of articles } \\ \text { - Immediate, unrestricted online access }\end{array}$

